\title{
Emergence of Carbapenem-Resistant Enterobacteriaceae in a Tertiary Care Hospital in Southern Thailand ${ }^{\dagger}$
}

\author{
Prerit Upadhyaya ARYAL ${ }^{1}$, Benjamas THAMJARUNGWONG ${ }^{2}$, \\ Kamonnut SINGKHAMANAN ${ }^{1}$, Paramee THONGSUKSAI ${ }^{2}$, \\ Natnicha INGVIYA ${ }^{2}$, Varaporn LAOHAPRERTTHISAN ${ }^{2}$, \\ Rungtip DARAYON ${ }^{3}$ and Mingkwan YINGKAJORN ${ }^{2, *}$
}

${ }^{1}$ Department of Biomedical Sciences, Faculty of Medicine, Prince of Songkla University, Songkhla 90110, Thailand

${ }^{2}$ Department of Pathology, Faculty of Medicine, Prince of Songkla University, Songkhla 90110, Thailand ${ }^{3}$ Infection Control Unit, Songklanagarind Hospital, Songkhla 90110, Thailand

("Corresponding author's e-mail: mingkwan.y@psu.ac.th)

Received: 17 May 2019, Revised: 22 July 2019, Accepted: 19 August 2019

\begin{abstract}
Carbapenem-resistant Enterobacteriaceae (CRE) is emerging as a major problem in healthcare settings globally, including Thailand, due to limited therapeutic options. We reported the detection, antimicrobial susceptibility profiles, and the presence of carbapenemase genes of CRE isolates obtained from Songklanagarind Hospital between July 2012 and June 2015. A total of 273 non-duplicated CRE isolates was recovered from 248 patients. The predominant organism was Klebsiella pneumoniae (183 [67.0\%]), followed by Escherichia coli (38 [13.9\%]). The susceptibility to 13 antibiotics was performed by disk diffusion assay. Most of the CRE isolates remained susceptible to amikacin. Minimum inhibitory concentrations (MIC) of carbapenems were determined by E-test. The $\mathrm{MIC}_{50}$ and $\mathrm{MIC}_{90}$ were varied among genera and species. Multiplex PCRs for the carbapenemase genes $b l a_{\mathrm{IMP}}$, bla $_{\mathrm{VIM}}$, bla $_{\mathrm{OXA}-48}, b a_{\mathrm{NDM}-}$ ${ }_{1}, b l a_{\mathrm{KPC}}$, and $b l a_{\mathrm{GES}}$ were performed. One hundred and seventy-eight out of these $273 \mathrm{CRE}$ isolates $(65.2$ $\%$ ) harbored either single or multiple carbapenemase genes. One hundred and fifty nine isolates harbored the bla NDM-1 $_{1}$ gene $(113 \mathrm{~K}$. pneumoniae, $25 \mathrm{E}$. coli, 17 E. cloacae, 2 Citrobacter freundii, 1 Enterobacter aerogenes, and 1 Pantoea agglomerans), 7 isolates carried bla $\mathrm{IMP}_{\mathrm{IM}}(4 \mathrm{~K}$. pneumoniae, $2 \mathrm{C}$. freundii, and 1 E. cloacae), 7 isolates possessed bla $a_{\text {OXA-48 }}(1 \mathrm{~K}$. pneumoniae, $5 \mathrm{E}$. coli, and $1 \mathrm{E}$. aerogenes $)$, whereas 3 and 2 isolates harbored bla $a_{\mathrm{NDM}-1}$ and bla $_{\mathrm{IMP}}(2 \mathrm{~K}$. pneumoniae and 1 E. cloacae $)$ and bla $\mathrm{NDM}-1_{\mathrm{N}}$ and bla $\mathrm{OXX}_{\mathrm{OA}}$ ${ }_{48}(1 \mathrm{E}$. coli and $1 \mathrm{E}$. cloacae), respectively. In conclusion, this study revealed the detection of CRE, with the majority of $K$. pneumoniae harboring $b l a_{\mathrm{NDM}-1}$ in this setting.
\end{abstract}

Keywords: Carbapenem resistance, Enterobacteriaceae, Carbapenemases, K. pneumoniae, NDM-1

\section{Introduction}

Carbapenems are antimicrobial agents from the $\beta$-lactam family which show the broadest spectrum of activity against Gram-negative bacteria [1]. Carbapenems are not inactivated by extended-spectrum $\beta$ lactamase (ESBL) or AmpC $\beta$-lactamase [2]. Hence, they are the drug of choice to treat infections caused by ESBL producers [3]. Enterobacteriaceae, which are resistant to antimicrobials of class carbapenem, are called carbapenem-resistant Enterobacteriaceae (CRE). Carbapenem resistance in Enterobacteriaceae

\footnotetext{
${ }^{\dagger}$ Presented at the International Conferences on Biomedical Sciences and Medical Technology 2019: June 20 - 21, 2019
} 
has been reported globally, and it has emerged as a major public health threat with a worldwide impact [4,5]. CRE have been increasingly detected in Southeast Asia, including Thailand [6-8]; the danger is coupled with the fact that the mortality rate for CRE infections is higher, due to limited therapeutic options [9].

Carbapenem resistance in Enterobacteriaceae is mainly through the production of 3 classes of carbapenemase enzymes, as classified in the Ambler classification. The most common carbapenemases reported from different geographical regions are KPC, GES (class A serine $\beta$-lactamases), NDM, IMP, VIM (class B metallo- $\beta$-lactamases), and OXA (class D oxacillinase). The production of AmpC-type $\beta$ lactamase, or ESBL, with low permeability of outer membrane proteins and efflux pump expressions, is also involved in carbapenem resistance $[5,10]$. The localization of the carbapenemase genes is either on chromosomes or plasmids. The mobile genetic elements, plasmids and transposons, are related to bacterial gene transmission leading to infection outbreaks [10]. KPC-producing Klebsiella pneumoniae was first isolated from an intensive care unit in North Carolina in 1996 [11]. However, the wide spread of carbapenemase-producing Enterobacteriaceae was undetected until 2000, and the first outbreak of KPCproducing K. pneumoniae was reported in 2001 in the US. This KPC-producing strain spread throughout the US and appeared in different countries such as Greece, Italy, and Israel [12]. NDM was first isolated in India, and OXA-48 in Turkey. They have been frequently reported from Europe, Asia, and North America [5]. In Thailand, the first report of NDM-1 and IMP-14a in Enterobacteriaceae was from Khon Kaen province in 2012 [13], while the first case of Enterobacteriaceae harboring bla $a_{\mathrm{KPC}-13}$ was reported from Bangkok in 2014. In 2015, the spread of carbapenem-resistant ST $340 \mathrm{~K}$. pneumoniae was also reported, with concern shown as to limiting its spread $[7,8]$.

The high prevalence of ESBL, along with the overuse of carbapenems, is widely considered to be the leading cause for the high incidence of CRE in Thailand. The use of carbapenems from 2010 to 2013 increased from approximately 2.1 to 3.1 million vials per year [14]. The rapid detection of CRE, along with the proper implementation of infection control measures, is important to prevent its spread. The aim of this present study was to investigate the prevalence of CRE over 3 years in Songklanagarind Hospital, the major tertiary care and referral center in Southern Thailand. We also studied the susceptibility profiles and characterized the main mechanisms of carbapenem resistance among these CRE isolates.

\section{Materials and methods}

This study was a retrospective cohort study conducted at Songklanagarind Hospital, an 863-bed tertiary level university hospital located in Southern Thailand, after obtaining approval from the Research Ethics Committee, Faculty of Medicine, Prince of Songkla University, Songkhla, Thailand (REC59-04305-2).

\section{Inclusion of CRE isolates}

All antimicrobial-resistant isolates belonging to the family Enterobacteriaceae that have been stored in $30 \%(\mathrm{~V} / \mathrm{V})$ glycerol broth at $-80{ }^{\circ} \mathrm{C}$ as a part of the routine work in the Microbiology Unit, Songklanagarind hospital between July 2012 and June 2015 were investigated. Those isolates were previously identified for their species level at the time of isolation from routine cultures by standard laboratory methods. The isolates were collected from both clinical specimens (urine, sputum, pus/ discharge, tissue, blood, and various body fluids), and from surveillance screening (rectal swab). The isolates were defined as CRE on the basis of non-susceptibility to any tested carbapenems (ertapenem, imipenem, and meropenem) via susceptibility testing. The Providencia, Proteus, or Morganella genera that demonstrated an MIC of $>1 \mu \mathrm{g} / \mathrm{mL}$ for imipenem alone were excluded from the study. Duplicate CRE isolates (i.e., those of the same species from the same specimen type) from the same patient in the same year were excluded. 


\section{Antimicrobial susceptibility testing}

The susceptibility testing of the Enterobacteriaceae isolates was carried out using the Kirby-Bauer disk diffusion method on Muller-Hinton agar plates, according to Clinical and Laboratory Standards Institute (CLSI) guidelines [15]. Commercial antibiotic discs from 2 manufacturers, Oxoid, Basingstoke, UK, and BD, Maryland, US, were used for the antimicrobial testing. The tested antibiotics were amikacin $(30 \mu \mathrm{g})$, ceftazidime $(30 \mu \mathrm{g})$, ceftriazone $(30 \mu \mathrm{g})$, cefotaxime $(30 \mu \mathrm{g})$, cefoxitin $(30 \mu \mathrm{g})$, ciprofloxacin $(5$ $\mu \mathrm{g})$, ertapenem $(10 \mu \mathrm{g})$, gentamicin $(10 \mu \mathrm{g})$, imipenem $(10 \mu \mathrm{g})$, meropenem $(10 \mu \mathrm{g})$, sulperazone $(30 \mu \mathrm{g})$, norfloxacin $(10 \mu \mathrm{g})$, and trimethoprim/sulfamethoxazole $(1.25 / 23.75 \mu \mathrm{g})$. The susceptible results were interpreted according to the CLSI guidelines [15]. E. coli ATCC $₫ 25922^{\mathrm{TM}}$ was used as the quality control for the antimicrobial susceptibility test. The MICs of ertapenem, imipenem, and meropenem were determined using commercial E-test strips (Liofilchem, Roseto degli Abruzzi, Italy).

\section{Detection of carbapenemases genes}

The bacterial DNA of CRE isolate was extracted by the boiling method. Briefly, an overnightgrown CRE isolate was centrifuged at $8,000 \mathrm{rpm}$ for $3 \mathrm{~min}$; then, the supernatant was discarded. The pellet was washed twice with normal saline. After washing, the pellet was mixed with $100 \mu$ of deionized water and boiled for $15 \mathrm{~min}$ at $100{ }^{\circ} \mathrm{C}$. The tube was immediately cooled on ice and centrifuged at 8,000 rpm for $8 \mathrm{~min}$. The supernatant was collected as DNA templates for further investigation.

All CRE isolates were tested for carbapenemase genes by multiplex PCR. The most prevalent carbapenemase genes, $b l a_{\mathrm{IMP}}, b l a_{\mathrm{VIM}}, b l a_{\mathrm{OXA}-48}, b l a_{\mathrm{NDM}-1}, b l a_{\mathrm{KPC}}$, and $b l a_{\mathrm{GES}}$, were investigated by using the primers described earlier [16,17]. The PCR reaction was conducted under the following conditions: 94 ${ }^{\circ} \mathrm{C}$ for $10 \mathrm{~min}$, followed by 36 cycles of $94{ }^{\circ} \mathrm{C}$ for $30 \mathrm{~s}, 52{ }^{\circ} \mathrm{C}$ for $40 \mathrm{~s}$, and $72{ }^{\circ} \mathrm{C}$ for $50 \mathrm{~s}$, with a final extension for $5 \mathrm{~min}$ at $72{ }^{\circ} \mathrm{C}$. Amplification products were analyzed by $2 \%$ agarose gel electrophoresis. The amplicons were sequenced at $1^{\text {st }}$ BASE (Malaysia), and the sequence of each gene was confirmed using the NCBI website (https://www.ncbi.nlm.nih.gov).

\section{Results and discussion}

\section{Distribution of CRE isolates}

During the study period, a total of 19,495 Enterobacteriaceae were isolated and tested for antimicrobial susceptibility. Only 273 non-duplicated CRE, isolated from 248 patients admitted at various wards of the hospital, met the study inclusion criteria. In a 6-month interval period during the study, CRE were isolated from 5 patients in July-Dec 2012, and reached 107 patients in Jan-June 2015, indicating the increasing trend of CRE being circulated in this setting (Figure 1).

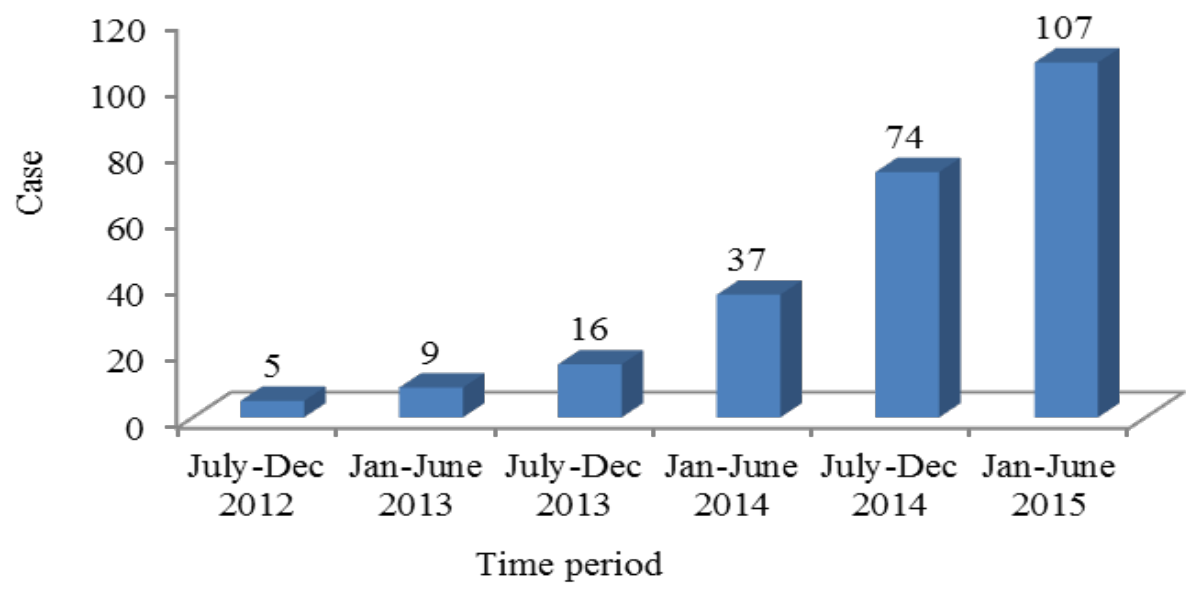

Figure 1 Number of CRE cases during July 2012 and June 2015. 
http://wjst.wu.ac.th

The most common species were $K$. pneumoniae (183 isolates, $67.03 \%$ ), followed by E. coli (38 isolates, $13.92 \%$ ), Enterobacter cloacae (35 isolates, $12.82 \%$ ), Citrobacter freundii (8 isolates, $2.93 \%$ ), Enterobacter aerogenes (4 isolates, $1.47 \%$ ), Pantoea agglomerans (2 isolates, 0.73 \%), Klebsiella ozanae (1 isolate, $0.37 \%$ ), Proteus mirabilis (1 isolate, $0.37 \%$ ), and Serratia liquefaciens (1 isolate, 0.37 $\%)$. Similar findings of CRE distribution were reported from Singapore and Malaysia, whereby the majority of the isolated CRE were $K$. pneumoniae, followed by E. coli and E. cloacae $[18,19]$. Nevertheless, the CRE species distributions were different from a previous study conducted in Thailand, in that E. cloacae $(67.9 \%)$ was found to be most predominant, whereas only 19.9 and $9.4 \%$ of $K$. pneumoniae and E. coli, respectively, were CRE [14]. The difference in CRE species distribution may be due to variations in geography or the study site. However, further studies in CRE prevalence in Thailand's different healthcare setting would set a benchmark to trace CRE incidence and prevalence.

Overall, CRE isolates were obtained from 252 samples, and mainly isolated from rectal swabs (surveillance culture), 182/273 (85.7\%). The rectal swabs were collected from patients staying near newly identified CRE patients (index case) who were admitted at the same ward during the same interval time. The surveillance culture was performed to identify the unrecognized CRE colonization, as one of the recommended strategies by the Center for Disease Control and Prevention (CDC), in order to control CRE transmission in a ward [20]. For index cases, the majority of clinical samples were obtained from catheter urine, followed by sputum, pus, midstream urine, blood, and body fluid (Table 1). Few numbers were isolated from tissue. This finding was similar to another previous study that highlighted specimens from the urinary tract, followed by the respiratory tract, gastrointestinal tract, bloodstream, tissue, and wound, as the frequent isolation site of CRE [18].

Ward-wide distribution of all specimens is shown in Table 1. A high rate of infection and colonization of CRE isolates was observed in our setting, which led to major concern. Notably, fifty-three percent $(n=37)$ of the clinical specimens, in addition to 86 percent $(n=156)$ of rectal swabs, were from patients in 3 major wards: intensive care units, surgical wards, and medical wards. Patients in these wards usually have a longer hospital stay and have indwelling devices. Previous studies [18,21] suggested length of the stay, antimicrobial exposure, and indwelling devices (intravascular lines, urinary catheter, endotracheal tube, and feeding tube) were risk factors for both infection and colonization with CRE. Furthermore, colonization with CRE is considered as a risk factor for subsequent CRE infections [22].

Table 1 Ward-wise distribution of clinical specimens and surveillance screening (rectal swab).

\begin{tabular}{|c|c|c|c|c|c|c|c|c|}
\hline \multirow{3}{*}{ Wards } & \multicolumn{8}{|c|}{ Number of specimen } \\
\hline & \multicolumn{4}{|c|}{ Sterile site $(\mathrm{N}=42)$} & \multicolumn{3}{|c|}{ Non-sterile site $(\mathrm{N}=30)$} & \multirow{2}{*}{$\begin{array}{c}\text { Rectal } \\
\text { swab }\end{array}$} \\
\hline & Blood & $\begin{array}{l}\text { Body } \\
\text { fluid }\end{array}$ & $\begin{array}{l}\text { Catheter } \\
\text { urine }\end{array}$ & Tissue & Sputum & $\begin{array}{l}\text { Pus/ } \\
\text { discharge }\end{array}$ & $\begin{array}{l}\text { Midstream } \\
\text { urine }\end{array}$ & \\
\hline Intensive care units & 3 & 2 & 1 & - & 5 & 1 & 3 & 41 \\
\hline Surgical & 1 & 1 & 6 & - & 4 & - & - & 55 \\
\hline Medical & 1 & 1 & 1 & - & 4 & 2 & 1 & 60 \\
\hline Orthopedics & 2 & - & 2 & - & - & 1 & 1 & 8 \\
\hline Obstetrics and gynecology & 1 & - & 3 & - & - & - & 1 & 3 \\
\hline Pediatrics & - & - & 2 & - & - & 1 & - & 4 \\
\hline Emergency & - & - & 5 & - & 1 & 1 & 1 & 1 \\
\hline Operation & - & - & 2 & 2 & - & 1 & - & 2 \\
\hline Trauma & - & 1 & 1 & - & - & 1 & - & 4 \\
\hline Others & - & 1 & 3 & - & 1 & - & - & 4 \\
\hline Total & 8 & 6 & 26 & 2 & 15 & 8 & 7 & 182 \\
\hline
\end{tabular}


http://wjst.wu.ac.th

Table 2 CRE susceptibility test results by Kirby-Bauer method.

\begin{tabular}{lllll}
\hline \multirow{2}{*}{ Antimicrobial class } & \multirow{2}{*}{ Antimicrobial agent } & \multicolumn{3}{c}{ Number of isolate (\%), total=273 } \\
\cline { 3 - 5 } & & Susceptible & Intermediate & Resistant \\
\hline Carbapenems & Imipenem & $55(20.1)$ & $16(5.9)$ & $202(74.0)$ \\
& Meropenem & $22(8.1)$ & $12(4.4)$ & $239(87.5)$ \\
Aminoglycosides & Ertapenem & $1(0.4)$ & $4(1.5)$ & $268(98.2)$ \\
& Amikacin & $243(89.0)$ & $13(4.8)$ & $17(6.2)$ \\
Cephalosporins & Gentamicin & $128(46.9)$ & $8(2.9)$ & $137(50.2)$ \\
& Cefoxitin & $1(0.4)$ & $3(1.1)$ & $269(98.5)$ \\
& Cefotaxime & $0(0.0)$ & $1(0.4)$ & $272(99.6)$ \\
& Ceftazidime & $2(0.7)$ & $0(0.0)$ & $271(99.3)$ \\
\multirow{2}{*}{ Other $\beta$-Lactam } & Ceftriaxone & $1(0.4)$ & $0(0.0)$ & $272(99.6)$ \\
Fluoroquinolones & Sulperazone & $9(3.3)$ & $17(6.2)$ & $247(90.5)$ \\
\multirow{2}{*}{ Folate pathway inhiitors } & Ciprofloxacin & $20(7.3)$ & $35(12.8)$ & $218(79.9)$ \\
& Norfloxacin & $98(35.9)$ & $24(8.8)$ & $151(55.3)$ \\
& Trimethoprim-sulfamethoxazole & $54(19.8)$ & $9(3.3)$ & $210(76.9)$ \\
\hline
\end{tabular}

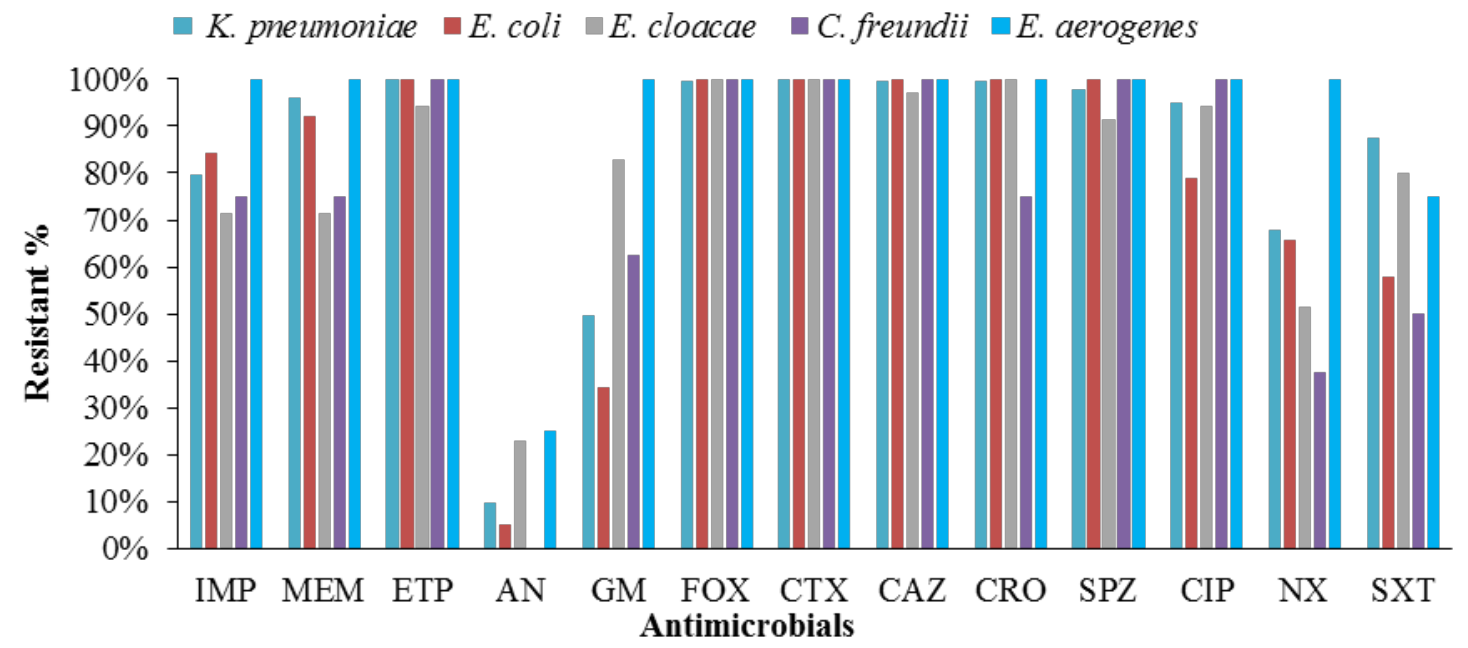

Figure 2 Antimicrobial resistant patterns of different Enterobacteriaceae species resistant to carbapenem IMP (imipenem); MEM (meropenem); ETP (ertapenem); AN (amikacin); GM (gentamicin); FOX (cefoxitin); CTX (cefotaxime); CAZ (ceftazidime); CRO (ceftriaxone); SPZ (sulperazone); CIP (ciprofloxacin); NX (norfloxacin); SXT (trimethoprim-sulfamethoxazole).

\section{Antimicrobial susceptibilities}

The susceptibility results are shown in Table 2. The susceptibility rates to meropenem and imipenem were 8.1 and $20.1 \%$, respectively. Of the 273 CRE isolates, only the single strain $(0.4 \%)$ was susceptible to ertapenem. From Figure 2, it is revealed that all of the CRE strains of K. pneumoniae ( $\mathrm{n}=$ 183), E. coli $(\mathrm{n}=38)$, C. freundii $(\mathrm{n}=8)$, and E. aerogenes $(\mathrm{n}=4)$ were resistant to ertapenem. Amikacin, an antimicrobial from the aminoglycosides group, displayed the most potent activity against 
CRE, with an overall susceptibility rate of $89.01 \%$ (243/273). A significant difference was observed between susceptibility to amikacin $(89.0 \%)$ and to gentamicin $(46.9 \%)$. However, there was a statistically significant difference between amikacin and gentamicin, as all the isolates ( $\mathrm{p}$-value $<0.05$ ) that were susceptible to gentamicin were also susceptible to amikacin. Almost all of the CRE isolates were resistant to $2^{\text {nd }}$ and $3^{\text {rd }}$ generations of cephalosporins (susceptibility rates ranging from $0-3 \%$ ). Of the $273 \mathrm{CRE}$ isolates, 2 isolates were found to be susceptible to ceftazidime, 1 isolate to each of cefoxitin and ceftriazone, and 9 isolates to sulperazone. None of the isolates were susceptible to cefotaxime. Only 20 isolates $(7.3 \%)$ were susceptible to ciprofloxacin, 98 isolates $(35.9 \%)$ to norfloxacin, and $54(19.8 \%)$ to trimethoprim-sulfamethoxazole.

$K$. pneumoniae isolates showed high levels of resistance to most of the antibiotics tested. The $\mathrm{MIC}_{50}$ for imipenem was $16 \mu \mathrm{g} / \mathrm{mL}$, and for meropenem and ertapenem was $\geq 32 \mu \mathrm{g} / \mathrm{mL}$. However, 90 and $50 \%$ susceptibility were reported for amikacin and gentamicin, respectively. E. coli isolates were 94 and $65 \%$ sensitive to amikacin and gentamicin, respectively, and none of the isolates were susceptible to cephalosporins. The $\mathrm{MIC}_{50}$ and $\mathrm{MIC}_{90}$ for all 3 tested carbapenems were $\geq 32 \mu \mathrm{g} / \mathrm{mL}$ for this species. Of 35 E. cloacae isolates, only 2 isolates were susceptible to ertapenem, and 10 were found susceptible to meropenem and imipenem. The $\mathrm{MIC}_{50}$ and $\mathrm{MIC}_{90}$ for ertapenem was $\geq 32 \mu \mathrm{g} / \mathrm{mL}$. The $\mathrm{MIC}_{50}$ was 12 $\mu \mathrm{g} / \mathrm{mL}$, and the $\mathrm{MIC}_{90}$ was $\geq 32 \mu \mathrm{g} / \mathrm{mL}$, for both imipenem and meropenem. All carbapenem-resistant $C$. freundii isolates developed $100 \%$ resistance to $2^{\text {nd }}$ and $3^{\text {rd }}$ generations of cephalosporin, ertapenem, and norfloxacin. The $\mathrm{MIC}_{50}$ were, respectively, $1.5,4$, and $4 \mu \mathrm{g} / \mathrm{mL}$ for imipenem, meropenem and ertapenem. The $\mathrm{MIC}_{90}$ were all $\geq 32 \mu \mathrm{g} / \mathrm{mL}$. Interestingly, all were found to be susceptible to amikacin. All E. aerogenes isolates showed resistance towards carbapenems, cephalosporins, quinolones, and gentamicin. The $\mathrm{MIC}_{50}$ and $\mathrm{MIC}_{90}$ of $\geq 32 \mu \mathrm{g} / \mathrm{mL}$ towards all tested carbapenems were reported. However, 3 E. aerogenes isolates showed susceptibility to amikacin.

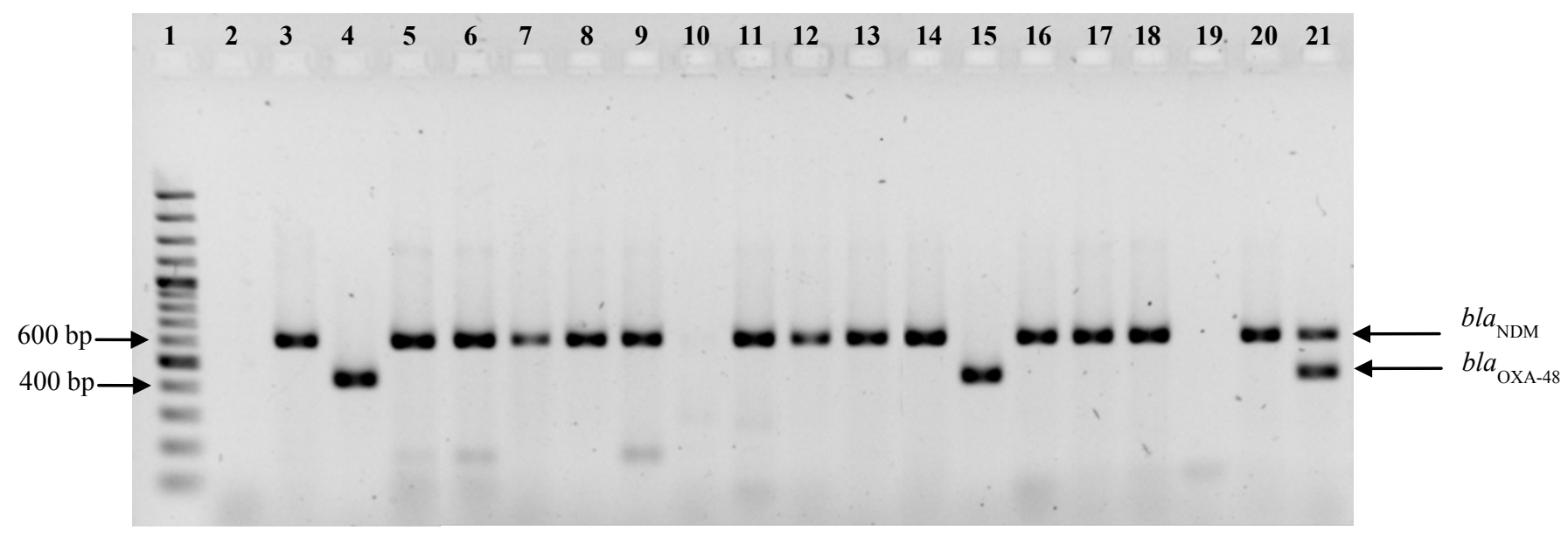

Figure 3 Example of agarose gel electrophoresis (2 \%) of multiplex PCR products following amplification with specific primers for carbapenemase genes. Lanes: (1) the 100 bp Sharp Ladder (RBCBioscience, New Taipei City, Taiwan), (2) negative control, (3-20) clinical isolates and (21) positive control for $b l a_{\mathrm{NDM}}(621 \mathrm{bp})$ and bla ${ }_{\mathrm{OXA}-48}(438 \mathrm{bp})$. 
http://wjst.wu.ac.th

\section{Carbapenem resistance mechanisms and antimicrobial susceptibility}

Carbapenem resistance in Enterobacteriaceae is mainly mediated by the enzymatic mechanism rather than the non-enzymatic mechanism [8]. In addition, carbapenemase is the most common, and major carbapenemase, KPC, GES, VIM, IMP, NDM-1, and OXA-48, are frequently detected in Enterobacteriaceae worldwide. Overall, out of 273 CRE, $173(63.4 \%)$ isolates were carrying a single carbapenemase gene, and $5(1.8 \%$ ) isolates had double carbapenemase genes (Table 3 and Figure 3). Out of 173 isolates, $159(91.9 \%)$ carried $b l a_{\mathrm{NDM}-1}$, and $7(4.1 \%)$ isolates harbored either the $b l a_{\mathrm{IMP}}$ or $b l a_{\text {OXA }}$ gene alone. The remaining 5 isolates carried a dual mechanism for carbapenemase production, including $b l a_{\mathrm{NDM}-1}+b l a_{\mathrm{IMP}}(3 / 273,1.1 \%)$ and $b l a_{\mathrm{NDM}-1}+b l a_{\mathrm{OXA}-48}(2 / 273,0.7 \%)$. Other types of carbapenemase genes, such as $b l a_{\mathrm{VIM}}, b l a_{\mathrm{KPC}}, b l a_{\mathrm{GES}}$, were not detected in this study. Antimicrobial susceptibility profiles of the Enterobacteriaceae harboring carbapenemase genes are summarized in Table 4. Ertapenem proved to be a reliable indicator of carbapenemase production, as all of the carbapenemase producing CRE isolates were $100 \%$ non-susceptible to ertapenem. Nearly all CRE isolates were resistant to $2^{\text {nd }}$ and $3^{\text {rd }}$ generation cephalosporins tested in this study, with amikacin being the exception. The overall susceptibility of CRE $(\mathrm{n}=273)$ to amikacin was $89.0 \%$. The susceptibilities to amikacin of bla $a_{\mathrm{NDM}-1}$-carrying $K$. pneumoniae, E. coli, and E. cloacae were 94.5, 92.0 and $88.2 \%$, respectively. Generally, most of the NDM-1 producers carry 16sRNA methylases genes and, as a result, show resistance to aminoglycosides [23]. The NDM-1-producing isolates remained susceptible to amikacin, which may be due to the loss of resistant genes which encode for 16sRNA methylase or bla $_{\mathrm{CMY}-4}[24,25]$.

We reported on the high prevalence of NDM-1-producing Enterobacteriaceae $(60.1 \%)$ among 273 CRE isolates. Our finding was similar to the study by Tran and colleagues, wherein NDM prevalence was $68.1 \%$ in all CRE [26]. A similar finding was observed in a collective survey from different countries, including the UK, India, Pakistan, and Bangladesh [23]. Indian subcontinent areas are supposed to be a reservoir for NDM-1 producing CRE isolates. The probable reason for CRE emergence is due to spread from hospitalized patients, who have a travel history in high risk areas [24,27]. In addition, the $b l a_{\mathrm{NDM}-1}$ gene is usually located on a plasmid, which can be easily transferred to other bacterial strains via horizontal gene transfer, resulting in drug-resistant phenotypes [23]. There is a concern of NDM-1 spreading from environment to community settings, as well as in hospitals settings. However, we did not perform environment sampling or clonal relatedness of CRE isolates; the origin or the source of NDM-1 spread in this setting remains unclear.

Table 3 Carbapenemase gene results for 273 CRE isolates.

\begin{tabular}{|c|c|c|c|c|c|c|c|c|}
\hline \multirow{2}{*}{ Organism } & \multirow{2}{*}{$\begin{array}{l}\text { No. } \\
\text { tested }\end{array}$} & \multicolumn{6}{|c|}{ No. of positive carbapenemase gene results } & \multirow{2}{*}{$\begin{array}{l}\text { No. tested } \\
\text { negative }\end{array}$} \\
\hline & & bla $_{\mathrm{KPC}}$ & $b^{b l a} a_{\mathrm{GES}}$ & bla $_{\mathrm{VIM}}$ & $b^{\prime l a} a_{\text {IMP }}$ & bla $_{\mathrm{NDM}-1}$ & bla $_{\text {OXA-48 }}$ & \\
\hline K. pneumoniae ${ }^{\mathrm{a}}$ & 183 & 0 & 0 & 0 & 4 & 115 & 1 & 63 \\
\hline E. coli ${ }^{\mathrm{b}}$ & 38 & 0 & 0 & 0 & 0 & 26 & 5 & 7 \\
\hline E. cloacae $^{\mathrm{c}}$ & 35 & 0 & 0 & 0 & 1 & 19 & 0 & 15 \\
\hline C. freundii & 8 & 0 & 0 & 0 & 2 & 2 & 0 & 4 \\
\hline E. aerogenes & 4 & 0 & 0 & 0 & 0 & 1 & 1 & 2 \\
\hline P. agglomerans & 2 & 0 & 0 & 0 & 0 & 1 & 0 & 1 \\
\hline K. ozanae & 1 & 0 & 0 & 0 & 0 & 0 & 0 & 1 \\
\hline P. mirabilis & 1 & 0 & 0 & 0 & 0 & 0 & 0 & 1 \\
\hline S. liquefaciens & 1 & 0 & 0 & 0 & 0 & 0 & 0 & 1 \\
\hline Total & 273 & 0 & 0 & 0 & 7 & 164 & 7 & 95 \\
\hline
\end{tabular}

$2 K$. pneumoniae isolates harbored $b l a_{\mathrm{NDM}-1}$ and $b l a_{\mathrm{IMP}}$

${ }^{\mathrm{b}} 1 \mathrm{E}$. coli isolate harbored $b_{l} a_{\mathrm{NDM}-1}$ and $b l a_{\mathrm{OXA}-48}$

${ }^{\mathrm{c}} 1$ E. cloacae isolate harbored $b l a_{\mathrm{NDM}-1}$ and $b l a_{\mathrm{IMP}}$ and 1 E. cloacae isolate harbored $b l a_{\mathrm{NDM}-1}$ and $b l a_{\mathrm{OXA}-48}$ 
http://wjst.wu.ac.th

Table 4 Antimicrobial susceptibility of CRE strains harboring carbapenemase gene.

\begin{tabular}{|c|c|c|c|c|c|}
\hline \multirow{3}{*}{$\begin{array}{l}\text { Antimicrobial } \\
\text { agent }\end{array}$} & \multicolumn{5}{|c|}{ Susceptible strain $[\mathrm{n},(\%)]$} \\
\hline & \multicolumn{3}{|l|}{$\boldsymbol{b} \boldsymbol{l} \boldsymbol{a}_{\mathrm{NDM}-1}$} & \multirow{2}{*}{$\begin{array}{l}\text { bla }_{\mathrm{IMP}} \\
\text { K. pneumoniae } \\
(\mathrm{N}=4)\end{array}$} & \multirow{2}{*}{$\begin{array}{l}\text { bla }_{\text {OXA }-48} \\
E . \text { coli } \\
(\mathrm{N}=5)\end{array}$} \\
\hline & $\begin{array}{l}\text { K. pneumoniae } \\
(\mathrm{N}=115)\end{array}$ & $\begin{array}{l}\text { E. coli } \\
(\mathrm{N}=26)\end{array}$ & $\begin{array}{l}\text { E. cloacae } \\
(\mathrm{N}=19)\end{array}$ & & \\
\hline Imipenem & $4,(3.5)$ & $0,(0.0)$ & $2,(11.8)$ & $0,(0.0)$ & $3,(60.0)$ \\
\hline Meropenem & $1,(0.9)$ & $0,(0.0)$ & $2,(11.8)$ & $0,(0.0)$ & $1,(20.0)$ \\
\hline Ertapenem & $0,(0.0)$ & $0,(0.0)$ & $0,(0.0)$ & $0,(0.0)$ & $0,(0.0)$ \\
\hline Amikacin & $107,(94.7)$ & $23,(92.0)$ & $15,(88.2)$ & $2,(50.0)$ & $5,(100.0)$ \\
\hline Gentamicin & $63,(55.8)$ & $16,(64.0)$ & $4,(23.5)$ & $2,(50.0)$ & $0,(0.0)$ \\
\hline Cefoxitin & $0,(0.0)$ & $0,(0.0)$ & $0,(0.0)$ & $0,(0.0)$ & $0,(0.0)$ \\
\hline Cefotaxime & $0,(0.0)$ & $0,(0.0)$ & $0,(0.0)$ & $0,(0.0)$ & $0,(0.0)$ \\
\hline Ceftazidime & $1,(0.9)$ & $0,(0.0)$ & $1,(5.9)$ & $0,(0.0)$ & $0,(0.0)$ \\
\hline Ceftriaxone & $1,(0.9)$ & $0,(0.0)$ & $0,(0.0)$ & $0,(0.0)$ & $0,(0.0)$ \\
\hline Sulperazone & $2,(1.8)$ & $0,(0.0)$ & $2,(11.8)$ & $0,(0.0)$ & $0,(0.0)$ \\
\hline Ciprofloxacin & $6,(5.3)$ & $6,(24.0)$ & $1,(5.9)$ & $1,(25.0)$ & $0,(0.0)$ \\
\hline Norfloxacin & $45,(39.8)$ & $11,(44.0)$ & $13,(76.5)$ & $2,(50.0)$ & $0,(0.0)$ \\
\hline $\begin{array}{l}\text { Trimethoprim- } \\
\text { sulfamethoxazole }\end{array}$ & $15,(13.3)$ & $12,(48.0)$ & $4,(23.5)$ & $1,(25.0)$ & $0,(0.0)$ \\
\hline
\end{tabular}

\section{Conclusions}

To our knowledge, this is the first study conducted in the southern region of Thailand that has reported the high prevalence of NDM-1 among CRE isolates. Most CRE isolates showed resistance to almost all antimicrobial agents, except amikacin. $K$. pneumoniae harboring bla $a_{\mathrm{NDM}-1}$ was the most prevalent in this setting. Our study is the first to investigate and report on NDM-1-producing E. cloacae from Thailand. The prevalence of CRE was higher in certain specific wards; therefore, strict prevention and infection control measures should be taken to prevent the spread of CRE in hospitals, as well as in the community.

\section{References}

[1] KM Papp-Wallace, A Endimiani, MA Taracila and RA Bonomo. Carbapenems: Past, present, and future. Antimicrob. Agents Chemother. 2011; 55, 4943-60.

[2] DL Paterson and RA Bonomo. Extended-spectrum beta-lactamases: A clinical update. Clin. Microbiol. Rev. 2005; 18, 657-86.

[3] KZ Vardakas, GS Tansarli, PI Rafailidis and ME Falagas. Carbapenems versus alternative antibiotics for the treatment of bacteraemia due to Enterobacteriaceae producing extendedspectrum beta-lactamases: A systematic review and meta-analysis. J. Antimicrob. Chemother. 2012; 67, 2793-803.

[4] P Nordmann, L Dortet and L Poirel. Carbapenem resistance in Enterobacteriaceae: Here is the storm! Trends Mol. Med. 2012; 18, 263-72.

[5] D van Duin and Y Doi. The global epidemiology of carbapenemase-producing Enterobacteriaceae. Virulence 2017; 8, 460-9.

[6] K Lunha, A Chanawong, A Lulitanond, C Wilailuckana, N Charoensri, L Wonglakorn, P Saenjamla, P Chaimanee, S Angkititrakul and P Chetchotisakd. High-level carbapenem-resistant 
http://wjst.wu.ac.th

OXA-48-producing Klebsiella pneumoniae with a novel OmpK36 variant and low-level, carbapenem-resistant, non-porin-deficient, OXA-181-producing Escherichia coli from Thailand. Diagn. Microbiol. Infect. Dis. 2016; 85, 221-6.

[7] T Netikul, H Sidjabat, D Paterson and P Kiratisin. Emergence of novel bla $\mathrm{KPC}-13)_{\text {among }}$ carbapenem-resistant Enterobacteriaceae in Thailand. Int. J. Antimicrob. Agents 2014; 44, 568-9.

[8] N Suwantarat and KC Carroll. Epidemiology and molecular characterization of multidrug-resistant Gram-negative bacteria in Southeast Asia. Antimicrob. Resist. Infect. Control. 2016; 5, 15.

[9] ME Falagas, GS Tansarli, DE Karageorgopoulos and KZ Vardakas. Deaths attributable to carbapenem-resistant Enterobacteriaceae infections. Emerg. Infect. Dis. 2014; 20, 1170-5.

[10] AM Queenan and K Bush. Carbapenemases: The versatile beta-lactamases. Clin. Microbiol. Rev. 2007; 20, 440-58.

[11] H Yigit, AM Queenan, GJ Anderson, A Domenech-Sanchez, JW Biddle, CD Steward, S Alberti, K Bush and FC Tenover. Novel carbapenem-hydrolyzing beta-lactamase, KPC-1, from a carbapenemresistant strain of Klebsiella pneumoniae. Antimicrob. Agents Chemother. 2001; 45, 1151-61.

[12] E Temkin, A Adler, A Lerner and Y Carmeli. Carbapenem-resistant Enterobacteriaceae: Biology, epidemiology, and management. Ann. N. Y. Acad. Sci. 2014; 1323, 22-42.

[13] B Rimrang, A Chanawong, A Lulitanond, C Wilailuckana, N Charoensri, P Sribenjalux, W Phumsrikaew, L Wonglakorn, A Kerdsin and P Chetchotisakd. Emergence of NDM-1- and IMP14a-producing Enterobacteriaceae in Thailand. J. Antimicrob. Chemother. 2012; 67, 2626-30.

[14] T Netikul and P Kiratisin. Genetic Characterization of Carbapenem-Resistant Enterobacteriaceae and the Spread of Carbapenem-Resistant Klebsiella pneumonia ST340 at a University Hospital in Thailand. PLoS One 2015; 10, e0139116.

[15] CLSI. Performance Standards for Antimicrobial Susceptibility Testing; $29^{\text {th }}$ Informational Supplement. CLSI document M100. Clinical and Laboratory Standards Institute, Wayne, PA, 2019.

[16] L Poirel, TR Walsh, V Cuvillier and P Nordmann. Multiplex PCR for detection of acquired carbapenemase genes. Diagn. Microbiol. Infect. Dis. 2011; 70, 119-23.

[17] C Dallenne, AD Costa, D Decre, C Favier and G Arlet. Development of a set of multiplex PCR assays for the detection of genes encoding important beta-lactamases in Enterobacteriaceae. $J$. Antimicrob. Chemother. 2010; 65, 490-5.

[18] ML Ling, YM Tee, SG Tan, IM Amin, KB How, KY Tan and LC Lee. Risk factors for acquisition of carbapenem resistant Enterobacteriaceae in an acute tertiary care hospital in Singapore. Antimicrob. Resist. Infect. Control. 2015; 4, 26.

[19] AR Zaidah, NI Mohammad, S Suraiya and A Harun. High burden of Carbapenem-resistant Enterobacteriaceae (CRE) fecal carriage at a teaching hospital: Cost-effectiveness of screening in low-resource setting. Antimicrob. Resist. Infect. Control. 2017; 6, 42.

[20] CDC. Available at: https://www.cdc.gov/hai/pdfs/cre/CRE-guidance-508.pdf, accessed April 2019.

[21] A Bhargava, K Hayakawa and E Silverman. Risk factors for colonization due to carbapenemresistant Enterobacteriaceae among patients exposed to long-term acute care and acute care facilities. Infect. Control Hosp. Epidemiol. 2014; 35, 398-405.

[22] TH McConville, SB Sullivan, A Gomez-Simmonds, S Whittier and AC Uhlemann. Carbapenemresistant Enterobacteriaceae colonization (CRE) and subsequent risk of infection and 90-day mortality in critically ill patients, an observational study. PloS One 2017; 12, e0186195.

[23] KK Kumarasamy, MA Toleman, TR Walsh, J Bagaria, F Butt, R Balakrishnan, U Chaudhary, M Doumith, CG Giske, S Irfan and P Krishnan. Emergence of a new antibiotic resistance mechanism in India, Pakistan, and the UK: A molecular, biological, and epidemiological study. Lancet Infect Dis. 2010; 10, 597-602.

[24] TR Walsh. Combinatorial genetic evolution of multiresistance. Curr. Opin. Microbiol. 2006; 9, 47682.

[25] D Yong, MA Toleman, CG Giske, HS Cho, K Sundman, K Lee and TR Walsh. Characterization of a new metallo-beta-lactamase gene, $b l a_{(\mathrm{NDM}-1)}$, and a novel erythromycin esterase gene carried on a unique genetic structure in Klebsiella pneumoniae sequence type 14 from India. Antimicrob. Agents Chemother. 2009; 53, 5046-54. 
http://wjst.wu.ac.th

[26] HH Tran, S Ehsani, K Shibayama, M Matsui, S Suzuki, MB Nguyen, DN Tran, VP Tran, DL Tran, HT Nguyen and DA Dang. Common isolation of New Delhi metallo-beta-lactamase 1-producing Enterobacteriaceae in a large surgical hospital in Vietnam. Eur. J. Clin. Microbiol. Infect. Dis. 2015; 34, 1247-54.

[27] N Gupta, BM Limbago, JB Patel and AJ Kallen. Carbapenem-resistant Enterobacteriaceae: epidemiology and prevention. Clin. Infect. Dis. 2011; 53, 60-7. 